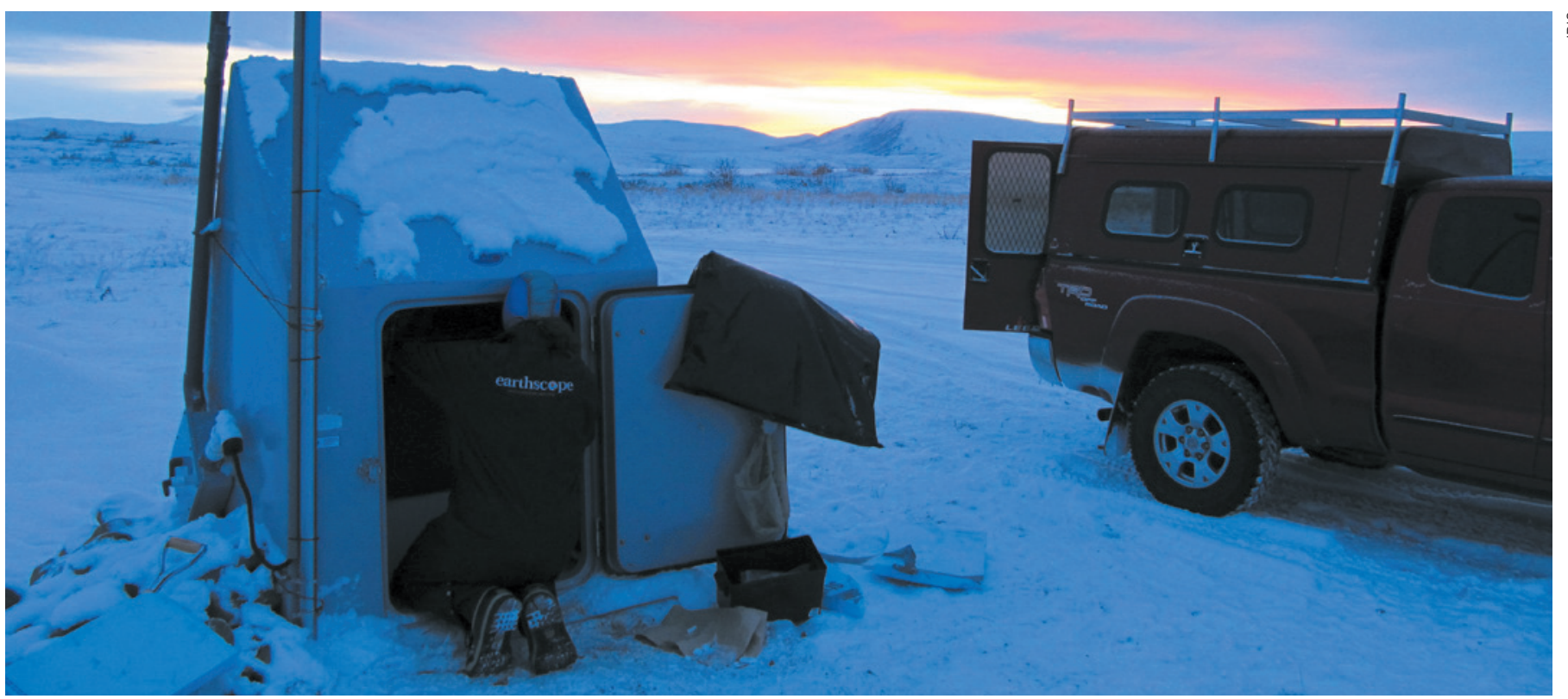

Scientists tested rugged new equipment for the Transportable Array near Toolik Lake, Alaska, in 2011.

GEOSCIENCE

\title{
US seismic array eyes its final frontier
}

\section{Moveable sensor grid will begin monitoring Alaska next summer.}

\section{BY ALEXANDRA WITZE}

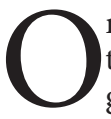

$\mathrm{n}$ Maine's rugged coast, just north of the tourist town of Boothbay, an underground seismometer is listening for earthquakes. Engineers activated it on $26 \mathrm{Sep}-$ tember, completing the US\$90-million Transportable Array, an ambitious effort to blanket the contiguous United States with a moveable grid of seismic monitors (see 'On the march').

Since 2004, the set of 400 seismometers, loaded on trucks, has marched gradually eastwards across the continent, from the Pacific coast across the Rocky Mountains and the Great Plains to reach the eastern seaboard. At each spot, technicians dig holes to bury the instruments in plastic tanks underground. The process has drawn the best picture yet of the North American part of Earth's mantle, reaching hundreds of kilometres beneath the surface. The array has illuminated how slowmotion earthquakes shimmy along the coast of the Pacific Northwest, and how molten rock rises in the hot spot deep beneath Yellowstone National Park in Wyoming.

"As the array has moved, the whole picture of what's under North America has gotten much sharper," says Andy Frassetto, a seismologist at the Incorporated Research Institutions for Seismology (IRIS) in Washington DC, which operates the stations.

Now, the Transportable Array's operators are looking to the far north, in what may be its toughest challenge yet. Having almost finished the job in the lower 48 states, the seismometers will start to be relocated next spring to Alaska - by far the most seismically active US state, and not thoroughly monitored yet. The project's seasoned engineers will have to fly many of the instruments to remote locations by helicopter, then drill into frozen ground and install the seismometers with battery packs to keep them working through the long northern winter. (A few additional stations will be installed across the Canadian border, in the Yukon Territory.)

The Transportable Array, along with other permanent and temporary seismic stations, is one of three cornerstones making up the larger EarthScope initiative. EarthScope was conceived as a way to combine different geophysical views of the deep Earth to provide data on a grand scale for researchers working across North America on all aspects of geoscience. EarthScope's second component comes in the form of Global Positioning System instruments that detect tiny changes in ground movement, such as those that occur along geological faults. The initiative's third component was a 3.2-kilometre-deep hole drilled into California's San Andreas fault, although the effort was marred when instruments lowered down the hole stopped working after just days (see Nature 459, 20-21; 2009).

But the first two parts of EarthScope are yielding plenty of insights. "We've learned a lot more by integrating things together than we would have by doing them separately," says Robert Smith, a geophysicist at the University of Utah in Salt Lake City, and an early leader of EarthScope.

When the Transportable Array was initiated in 2004, with funding from the US National Science Foundation, it was just a single station outside San Diego, California. Now, its 400 stations are arranged at 70-kilometre intervals in a regular grid. Each stays in the ground for roughly two years before being dug up and redeployed to the array's leading edge. The stations capture seismic waves travelling through the ground from earthquakes near and far information that geoscientists can use to probe deeper into Earth, and with greater regularity, than with other, smaller arrays.

Among other things, the EarthScope seismic data have allowed researchers to construct images of the deep Earth, rather like a geological computerized-tomography scan (Y. Yang 


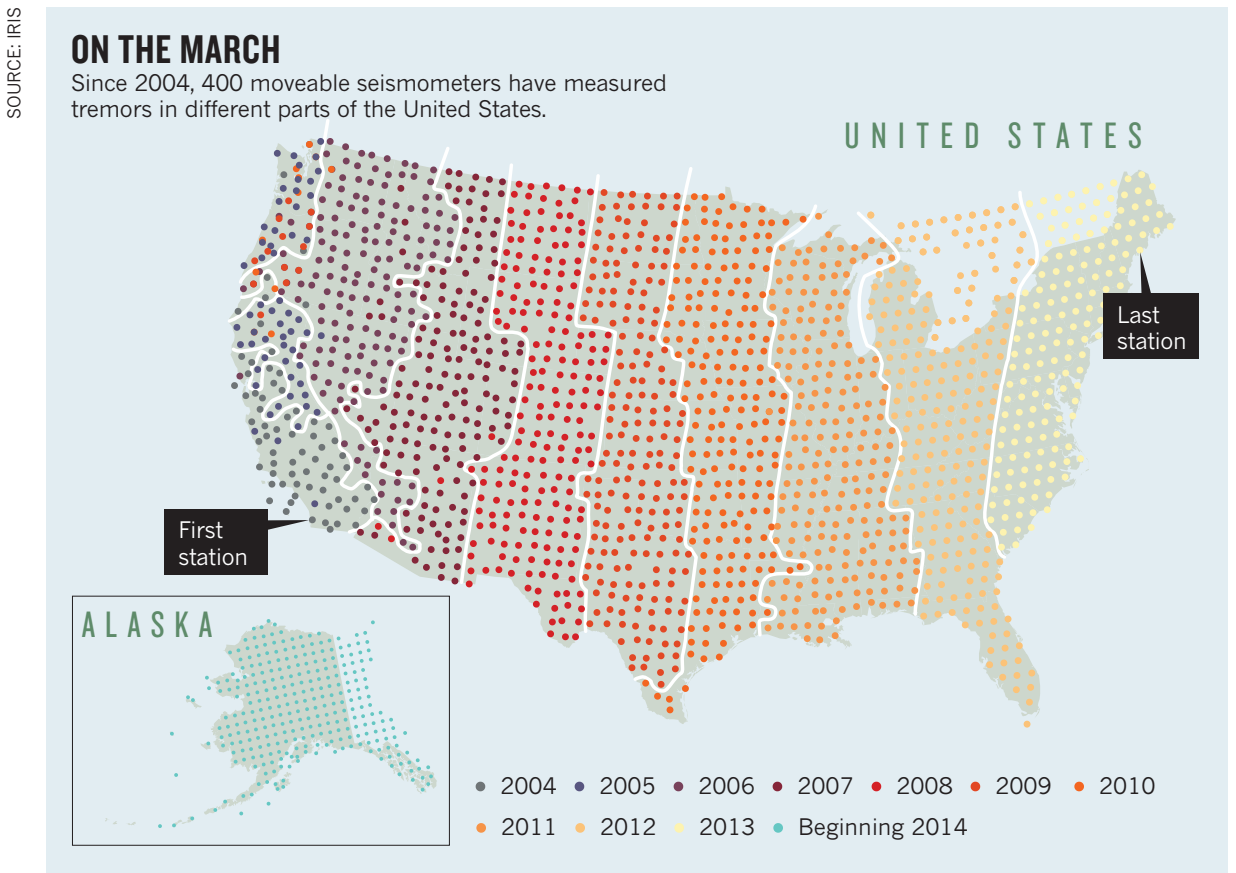

J. Geophys. Res. 113, B12310; 2008), and to trace shaking from great earthquakes, such as Japan's Tohoku quake in March 2011, to calculate how a fault ruptured half a world away (M. Ishii Earth Planets Space 63, 609-614; 2011).

Some seismologists worried that things might get boring as the array trundled across the United States, leaving the seismically exciting west for the flatter east. But that did not happen; in fact, the latest data show that the upper part of Earth's mantle east of the Rocky Mountains is just as complex as that in the west, says Suzan van der Lee, a geophysicist at Northwestern University in Evanston, Illinois, who presented the work on 30 October at the annual meeting of the Geological Society of America in Denver, Colorado. The array also captured the surprising magnitude-5.8 earthquake in Virginia in August 2011, and the seismic shaking caused by Hurricane Sandy as it swept the eastern seaboard in October 2012.

Array deployments went so well that the project had money remaining and was able to add 60 previously unplanned Canadian stations in southern Ontario and Quebec, to study a zone of seismicity along the St Lawrence seaway. Other dreams didn't transpire; some scientists wanted to ramp up from taking 40 observations per second to 100 . Such a change would have overloaded the datastorage and delivery systems, says the array's manager, Robert Busby of IRIS.

Now, as the array prepares to leave the east coast, project managers are tackling the logistics of the five-year, \$40-million move to Alaska as soon the snow melts there next spring. About 160 of the 400 stations currently in the east will remain behind, as part of a plan drawn up by four federal agencies to fill in seismic monitoring gaps in heavily populated areas and near nuclear power plants.

EarthScope managers will use the money saved to buy more durable equipment for Alaska, where the conditions are notoriously tough on outdoor gear. Busby's team is acquiring high-capacity lithium-ion batteries that can be charged by solar panels in the summer and survive all winter. Engineers are also developing methods to relay data by satellite phone, because the mobile-phone network in Alaska covers only a fraction of the state.

And instead of burying seismometers in plastic containers, which could break as the ground thaws and freezes, the team plans to install them deep in permanently frozen ground or solid rock. They have developed a lightweight drill rig that can be carried easily by helicopter, because many of the seismic sites have no road access.

Logistical problems are one reason that the stations will be spaced less densely in Alaska than in the 48 contiguous states - every 85 kilometres instead of every 70 . Even so, they will provide a sharper and deeper view of what is happening beneath Alaska than ever before. "It'll make such a difference in so many ways," says Peter Haeussler, a geologist with the US Geological Survey (USGS) in Anchorage, Alaska. "There will be seismometers in the parts of the state that have never had them."

Alaska also has some of the most complex geology in North America, with the Pacific crustal plate slamming into and diving under the continent. Yet little has been done to probe the underlying crust and mantle, mainly because instrumenting the entire state is so expensive. "We have sort of a 'zeroth' order of understanding," says Rick Saltus, a USGS geophysicist in Denver. Now, he says, "we'll get the first order". 